\title{
A CRIAÇÃO DO COLÉGIO UNIVERSITÁRIO DA UNIVERSIDADE RURAL DO ESTADO DE MINAS GERAIS (1964-1965): ENTRE O SUPERIOR E O AGROTÉCNICO ${ }^{1}$
}

\author{
Joana D'Arc Germano Hollerbach²
}

\section{RESUMO}

O objetivo deste artigo é analisar o processo de decisão sobre a criação do Colégio Universitário na Universidade Rural do Estado de Minas Gerais (UREMG), entre 1964 e 1965. O baixo financiamento, a dúvida sobre o caráter da formação no secundário e a necessidade de atendimento às demandas do capital marcavam a disputa entre a criação do Colégio Universitário e a manutenção do Agrotécnico. A pesquisa, realizada a partir da consulta a documentos do arquivo histórico da Universidade Federal de Viçosa (UFV), indica que a manutenção do Curso

1 O presente artigo é uma versão ampliada do trabalho apresentado no XIII Congreso Iberoamericano Historia de la Educación Latinoamericana, realizado em Montevideo/Uruguai, entre 28/02/2018 e 03/03/2018, promovido pela Sociedad Uruguaya de Historia de la Educación (Suhe).

${ }^{2}$ Universidade Federal de Viçosa (UFV), Viçosa/MG, Brasil. 
Agrotécnico foi vencida pelo argumento da falta de recursos e pela ineficiência do curso técnico em manter os jovens afastados da disputa pelas poucas vagas do ensino superior. A análise evidencia a disputa entre capital e trabalho na definição de um modelo de formação para o jovem brasileiro.

Palavras-chave: Colégio Universitário, Curso Agrotécnico, ensino técnico, ensino secundário, Minas Gerais.

\title{
LA CREACIÓN DEL COLEGIO UNIVERSITARIO DE LA UNIVERSIDAD RURAL DEL ESTADO DE MINAS GERAIS (1964-1965): ENTRE EL SUPERIOR Y EL AGROTÉCNICO
}

\section{RESUMEN}

Este artículo se propone a analizar el proceso de decisión sobre la creación del Colegio Universitario en la Universidad Rural del Estado de Minas Gerais (UREMG), entre 1964 y 1965. La baja financiación, la duda sobre el carácter de la formación en la secundaria y la necesidad de atendimiento a las demandas del capital marcaban la disputa entre la creación del Colegio Universitario y la manutención del Agrotécnico. La investigación realizada a partir de la consulta a los documentos del Archivo Histórico de la Universidade Federal de Viçosa (UFV) indica que la manutención del curso agrotécnico fue vencida por el argumento de falta de recursos y por la ineficiencia del curso técnico en mantener a los jóvenes alejados de la disputa por las pocas plazas de la enseñanza superior. El análisis nos indica la disputa entre capital y trabajo en la definición de un modelo de formación para el joven brasileño.

Palabras clave: Colegio Universitario, Curso de Tecnico Agricola, enseñanza técnica, enseñanza secundaria, Minas Gerais.

\section{THE FOUNDATION OF THE UNIVERSITY COLLEGE IN THE RURAL UNIVERSITY OF MINAS GERAIS STATE (1964-1965): BETWEEN THE HIGHER EDUCATION AND THE AGROTECHNIC}

\begin{abstract}
This article aims to analyze the decision-making process on the foundation of the University College in the Rural University of Minas Gerais State (UREMG) between 1964 and 1965. Low funding, the doubt about the nature of secondary education, and the need to meet the capital demands marked the dispute between the foundation of the University College and the maintenance of the Agrotechnic. The research carried out from the consultation of documents from the Universidade Federal de Viçosa (UFV) Historical Archive indicates that the maintenance of the agrotechnical course was overcome by the argument of the lack of resources and by the inefficiency of the technical course in keeping the young people away from the dispute for the few vacancies of higher education. The analysis indicates the dispute between capital and labor in the definition of a training model for young Brazilian.
\end{abstract}

Keywords: University College, Agricultural Technician Course, technical education, high school; Minas Gerais. 


\section{LA CREATION DU COLLEGE UNIVERSITAIRE DE L'UNIVERSITE RURALE DE MINAS GERAIS (1964-1965): ENTRE LE SUPERIEUR ET L'AGROTECHNICIEN}

\section{RÉSUMÉ}

Cet article vise à analyser le processus de décision concernant la création du Collège universitaire de l'Université Rurale de l'État du Minas Gerais (UREMG), entre 1964 et 1965. Le faible financement, le doute sur le caractère de la formation au niveau secondaire et la nécessité de satisfaire les exigences du capital marquaient le litige entre la création du Collège Universitaire et le maintien de l'Agrotechnique. La recherche réalisée à partir de la consultation des documents des Archives Historiques de l'Universidade Federal de Viçosa (UFV) indique que le cours Agrotechnique a été supprimé faute de ressources et à cause de son inefficacité à maintenir les jeunes éloignés du conflit causé par le peu de places vacantes dans l'enseignement supérieur. L'analyse nous montre la dispute entre le capital et la définition du modèle de la formation pour le jeune brésilien.

Mots-clés: Collège universitaire, Cours de Technicien Agricole, enseignement technique, enseignement secondaire, Minas Gerais. 


\section{INTRODUÇÃO}

O intuito deste trabalho é discutir o processo de decisão sobre a criação do Colégio Universitário (Coluni) na Universidade Rural do Estado de Minas Gerais (UREMG)3, entre 1964 e 1965. Os colégios universitários foram criados a partir da Lei n. 4.024/1961, artigo 79, § $3^{\circ}$, com o objetivo de preparar os jovens estudantes do ensino secundário para o acesso aos cursos superiores. Tratava-se exclusivamente da oferta do terceiro ano do ciclo colegial pelas universidades brasileiras.

$\mathrm{Na}$ pesquisa foram localizados seis colégios universitários, criados no período em que o artigo 79 ficou em vigor, de 1961 até sua revogação em 1969. Na UREMG, a possibilidade de criação do Colégio Universitário, levada à discussão no conselho superior em 1964, trouxe um questionamento: manter ou não o Curso Agrotécnico.

O Curso Agrotécnico formava técnicos em agropecuária no nível médio e demandava recursos do escasso financiamento público da Universidade, à época vinculada ao governo do estado de Minas Gerais. O debate estabelecido nas instâncias superiores da UREMG nos aproxima da atual polêmica que se estabelece no Brasil, envolvendo as mudanças trazidas pela reforma do ensino médio, os limites estabelecidos pela Emenda Constitucional n. 95/2016 (que limita os gastos públicos primários) e o sentido do ensino médio. Esse debate não representa novas problemáticas para a educação brasileira, e o caso da UREMG nos exemplifica isso. O baixo financiamento, a dúvida sobre o caráter da formação do jovem no ensino secundário e a necessidade de atendimento às demandas do capital marcam esse campo de disputa.

\footnotetext{
3 A Escola Superior de Agricultura e Veterinária (Esav) foi inaugurada em 1926. Em 1949, foi estadualizada pelo governo do estado de Minas Gerais, sendo criada então a Universidade Rural do Estado de Minas Gerais (UREMG). Em 1969, a UREMG foi federalizada e convertida em Universidade Federal de Viçosa (UFV). Disponível em: http://www.dvt.ufv.br/?page_id=177. Acesso em: nov. 2017. Neste trabalho vamos usar o nome da instituição conforme o momento histórico citado.
} 
A análise apresentada aqui nos indica a manutenção da disputa entre capital e trabalho na definição de um modelo de formação para o jovem brasileiro, ontem e hoje. A contradição presente historicamente nas políticas públicas para o ensino secundário no Brasil permanece: temos que formar o jovem para o trabalho, mas não queremos formar nem muitos jovens, nem amplamente todos que têm acesso a esse nível de escolarização. A histórica exclusão dos jovens mais pobres é confirmada a cada novo documento e renovada a cada nova proposta de mudança.

\section{ENSINO SECUNDÁRIO E ENSINO SUPERIOR: DISPUTAS INTESTINAS}

Desde seus primórdios a UFV manteve, entre seus estudantes, jovens cursando o ensino secundário. A preocupação com a formação básica era percebida nas ações de Peter Henry Rolfs, agrônomo trazido dos Estados Unidos para organizar a Escola Superior de Agricultura e Veterinária (Esav) nos moldes dos Grand Colleges norte-americanos. Chegando a Viçosa, nos anos 1920, Rolfs logo percebeu a precária formação da mão de obra local para o desempenho das funções de construção do campus. Para minimizar essa dificuldade, refletida no atraso do cronograma de execução das obras, Rolfs criou uma sala de alfabetização para os funcionários da construção civil, as chamadas Classes Anexas.

Além desse recurso emergencial, que de fato não alterou muito a condição desses trabalhadores (até hoje a construção civil no campus emprega trabalhadores com pouca e até nenhuma formação escolar), havia os cursos regulares para atendimento de jovens ligados ao campo. Eram os cursos para capatazes e o Curso de Técnico em Agropecuária ofertado pelo Colégio Agrícola o Agrotécnico, este, sim, de maior status na Escola, só menos importante que o Curso de Agronomia. 
No entanto, o ensino secundário no Brasil, naquele momento, ainda era uma raridade entre a população mais pobre. Recorremos a Florestan Fernandes, em sua obra clássica Educação e Sociedade no Brasil (1966), para compreendermos melhor esse cenário. $O$ autor reconhece os avanços alcançados com as ações desenvolvidas pelos governos brasileiros no sentido de ampliar os níveis de escolarização da população até aquele momento - os anos 1960. No que diz respeito ao ensino primário, ainda havia problemas estruturais importantes a serem vencidos. Entre esses problemas, destacam-se a falta de recursos destinados à escola primária e os níveis extremos de pobreza que ameaçavam a população que dependia da escola pública. E nesse cenário adverso, em algumas regiões do País, o ensino primário se converteu "em privilégio social" (FERNANDES, 1966, p. 18). O ensino primário era pré-requisito para o ensino secundário, conforme preconizava o artigo 36, da Lei n. 4.024/1961:

\footnotetext{
Art. 36. O ingresso na primeira série do 1o ciclo dos cursos de ensino médio depende de aprovação em exame de admissão, em que fique demonstrada satisfatória educação primária, desde que o educando tenha onze anos completos ou venha a alcançar essa idade no correr do ano letivo (BRASIL, 1961).
}

Sobre o ensino médio e superior, o autor é categórico ao destacar a involução que esse nível de ensino sofreu em relação ao ensino primário, em todos os sentidos - número de matrículas, de vagas de professores habilitados e de conclusões de curso. Essa situação levava àquilo que o autor chamou de "caráter seletivo" do ensino médio e superior. Com a lacuna deixada pelo Estado na formação de grau médio, a iniciativa privada era, então, a alternativa das classes mais abastadas na formação de seus jovens. Assim, impunha-se "uma dura realidade, eliminando quase por completo, nas áreas mais desprotegidas, o aluno pobre e até a classe média das oportunidades educacionais asseguradas por esse tipo de ensino, principalmente na esfera da instrução ginasial e colegial" (FERNANDES, 1966, p. 21). Essa seleção por questões econômicas distanciava o País de seu futuro democrático buscado pela República, mas afastado 
sistematicamente pelos padrões aristocráticos ainda persistentes na educação brasileira naquele momento.

O ensino superior vivia um relativo equilíbrio entre a oferta pelo poder público e a iniciativa privada, e as escolas superiores públicas tinham melhores condições de atender à demanda para esse nível de ensino. Aqui o problema era de outra ordem: o reduzidíssimo número de jovens que conseguiam alcançar esse patamar de formação. De cada 100 crianças que tinham a chance de concluir o ensino primário, apenas três concluíam o ensino superior 4 (FERNANDES, 1966, p. 23). Esse vácuo na formação dos jovens brasileiros, em um período de reestruturação do País, trazia inconformação ao autor, que reconhecia, nesses dados, a distância que as políticas públicas se encontravam para atender às necessidades educacionais. Florestan Fernandes afirmava que:

\footnotetext{
O que espanta, nesses dados, é a distribuição vertical das oportunidades educacionais. Por pouco que se pretenda exagerar as coisas, elas traduzem um estado de fato alarmante, que não pode perdurar num país que pretenda industrializar-se, democratizar o poder a riqueza, aproveitar construtivamente os recursos tecnológicos e morais da civilização científica e ter posição autônoma na estrutura internacional de poder (FERNANDES, 1966, p. 23).
}

Para o sociólogo, o que definia esse percurso e as chances (ou não) de uma criança ou jovem alcançar patamares mais elevados na formação eram critérios herdados das estruturas sociais aristocráticas do período imperial. Nessas condições o acesso se dava por uma seleção que dependia de circunstâncias externas à escola, como as condições de renda (FERNANDES, 1966, p. 24).

\footnotetext{
4 O professor da Universidade do Estado do Rio de Janeiro (Uerj), Zacarias Gama, em entrevista ao periódico Carta Maior, em 2014, afirmou que "a expansão do sistema de ensino superior é uma necessidade estratégica e inadiável" (LOPES, 2014). Segundo Cibele Yahn de Andrade (2012), pesquisadora do Núcleo de Estudos de Políticas Públicas (Nepp) da Universidade Estadual de Campinas (Unicamp), o porcentual de jovens entre 18 e 24 anos que têm acesso ao ensino superior é de 19\%, de acordo com os dados da Pesquisa Nacional por Amostra de Domicílios (PNAD) de 2009. A desigualdade persiste.
} 
A partir da Lei n. 4.024/1961, o ensino de grau médio se subdividia em ginasial e colegial. O colegial poderia ser cursado como secundário, técnico ou como formação de professores para o pré-primário e primário. Entre os cursos técnicos, o ensino agrícola era o que apresentava os menores indicadores de matrícula (FERNANDES, 1966).

Entretanto, a busca pela formação no nível superior foi tomando contornos diferenciados ao longo dos anos 1960, o que levava um número de jovens maior que o número de vagas disponíveis a ascender aos estudos superiores. Essa demanda vinha sendo reprimida especialmente pelo encaminhamento dos jovens à formação nos cursos técnicos de nível médio.

O Brasil, no início dos anos 1960, acumulava várias mudanças de ordem econômica que exigiam um novo perfil de formação profissional. O esgotamento do modelo de economia que sustentava o País desde o período da colonização agricultura de exportação - já não atendia às novas configurações da economia mundial, na qual o Brasil se inseria perifericamente. A industrialização batia às portas desde os anos 1950, depois que a indústria de base se tornou um componente importante na economia nacional (WARDE, 1979).

Nesse contexto, a dinâmica de exploração dos trabalhadores, aliada à sua exclusão crescente dos processos decisórios na sociedade brasileira, criava um clima de instabilidade. A mobilização de alguns setores da sociedade buscava uma alternativa para os problemas que vinham sendo enfrentados pelos trabalhadores. Alguns segmentos se organizavam em busca de maiores direitos, com o apoio de políticos e de alguns governantes. Os reflexos dessas demandas ecoavam nas propostas do Poder Executivo nacional. Na avaliação de Warde (1979),

Foram feitas duas tentativas nos governos de J. Quadros e J. Goulart no sentido de corrigir as distorções estruturais do país, sob o modelo nacionalista de desenvolvimento e sob a intenção de recuperar e redefinir a aliança de classes. Entretanto, as medidas "revolucionárias" apregoadas por Goulart, nos últimos meses do seu governo foram insuficientemente assustadoras para a burguesia que já vinha num 
processo crescente de abandono daqueles princípios ideológicos que foram o elo da sua aliança com o operariado industrial (WARDE, 1979, p. 69).

Esse cenário, à primeira vista promissor, não lançou reflexos no financiamento das universidades, que se viam cada vez mais sem condições de atendimento da demanda por mais vagas, que crescia a cada ano, especialmente nos cursos mais concorridos, medicina e engenharia. A figura do "excedente" passou a perturbar o sono de muitos - candidatos e administradores, públicos e privados. A matrícula obrigatória dos excedentes onerava as instituições públicas, que sem o respectivo aporte de verbas adicionais, se viam às voltas com orçamentos insuficientes para os gastos ordinários. Essa quebra no orçamento prejudicava a qualidade dos cursos e a formação dos estudantes.

Com a reforma Rivadávia, estabelecida pelo Decreto 8.659/19115, o vestibular passou a ser o fiel da balança a definir quem teria acesso ao ensino superior ou não. Todavia, a figura do candidato excedente criava um constrangimento legal que trazia sérios problemas às instituições de ensino. Isso porque havia aprovação para os candidatos que alcançavam nota igual ou superior a cinco, induzindo à interpretação de direito à vaga. Segundo Luiz Antônio Cunha (1988):

\begin{abstract}
A legislação dos exames vestibulares dava margem a interpretar a aprovação - isto é, a nota igual ou superior a cinco - como dando direito à matrícula, apesar da política de numerus clausus $^{6}$ vigorar desde 1925. Sucessivas medidas do governo federal, orientadas pelos ventos da conjuntura política, davam sustentação a essa interpretação. Já em 1951, uma lei aprovada pelo Congresso Nacional autorizava as instituições particulares de ensino superior a matricular os candidatos aprovados naquele ano nos exames vestibulares às escolas oficiais, mas recusados por falta de vagas (CUNHA, 1988, p. 88).
\end{abstract}

\footnotetext{
5 A Reforma Rivadávia institui o exame vestibular. Antes disso, os exames para acesso ao ensino superior eram feitos de forma isolada, pelo Colégio Pedro II, ou por instituições credenciadas, por disciplina ou integralmente.

${ }^{6}$ Número restrito, nesse caso, número restrito de vagas.
} 
Os inúmeros egressos dos cursos superiores, todavia, não encontravam no mercado de trabalho colocação compatível com a formação universitária, gerando uma crise educacional. Os gastos com a formação de nível superior se perdiam no mercado de trabalho, que não absorvia todos os egressos. E um desempregado com curso superior tornava-se um peso morto na economia do País. Na análise de Cunha:

\begin{abstract}
Durante a República Populista (1945-64), o ensino superior brasileiro encontrava-se dilacerado por contradições, principalmente pela crise de realização social do seu produto: o profissional diplomado. A expansão de vagas e, consequentemente, dos diplomados, levava ao mercado de trabalho anualmente, muitos jovens à procura de emprego "compatível" com os padrões socialmente definidos de poder, de remuneração e de prestígio. Todavia, o crescimento das oportunidades de emprego não se dava no mesmo ritmo do aumento dos diplomados. Nos últimos anos da República Populista, os efeitos do processo de monopolização sobre a estrutura de emprego foram ampliados pela radicalização política dos movimentos sociais e pela espiral inflacionária. O resultado imediato foi a elevação dos requisitos educacionais, a desvalorização econômica e simbólica dos diplomas, o subemprego e o desemprego (CUNHA, 1988, p. 37).
\end{abstract}

Era necessário conciliar a formação da mão de obra e as demandas do mercado de trabalho, de modo a garantir o andamento da economia sem prejuízo com a formação de excedentes, tanto do ponto de vista quantitativo quanto qualitativo.

A criação do Coluni se insere, portanto, em um contexto em que a Instituição tinha que administrar os parcos recursos disponíveis e assim optar por determinada formação para seus estudantes em detrimento de outra. A questão financeira não era o único fator que influenciaria a decisão, concorrendo também os aspectos acadêmicos e políticos. 


\section{A CRIAÇÃO DO COLUNI: ENTRE O SUPERIOR E O AGROTÉCNICO, FARINHA POUCA, MEU PIRÃO PRIMEIRO ${ }^{7}$}

A discussão sobre a criação do Colégio Universitário remonta ao ano de 1962. A ata da reunião do Conselho Universitário da UREMG, do dia 02/10/1962, tem como ponto de pauta a apreciação de modificações em seus ordenamentos legais, em função das mudanças advindas da Lei n. 4.024, de 20 de dezembro de 1961. O Conselho solicitou ao Governo do estado, "através de seus órgãos jurídicos, promover o ante-projeto de lei reestruturando a UREMG" (UNIVERSIDADE..., 1962, Ata n. 94). Posteriormente, foi designada uma comissão para "estudar o parágrafo $3^{\circ}$, do art. 79, da Lei de Diretrizes e Bases da Educação Nacional", que autorizava a criação dos colégios universitários.

Em ofício de 22 de outubro de 1962, a Comissão encaminhou ao reitor Flamarion Ferreira a avaliação da Lei n. 4.024/61, que incluía algumas considerações sobre o Colégio Agrícola ${ }^{8}$ que funcionava anexo à UREMG. $\mathrm{O}$ documento entregue ao reitor trazia como sugestão a manutenção do Colégio Agrícola, desde que reestruturado, além das seguintes: administração própria (incluindo corpo docente, estrutura física, especialmente dormitório e orçamento) e currículo alterado, contemplando a possibilidade de opção no terceiro ano entre duas modalidades: exclusivamente técnico ou exclusivamente de cultura geral, para alunos que desejassem cursar as Escolas Superiores. Nesse último caso, poderia haver matrícula a partir do terceiro ano para alunos egressos de outras escolas. Assim previa o documento:

\footnotetext{
7 Há um ditado popular no Brasil, falado em todo o País desde priscas eras: farinha pouca, meu pirão primeiro. Usado sempre para justificar a distribuição pouco equilibrada de recursos desde o almoço em família até oportunidades abstratas de se alcançar alguma coisa e, inclusive, recursos públicos. Geralmente a referência se dá em tom pejorativo, indicando uma sombra de desonestidade ou de egoísmo nos mais espertos que conseguem se beneficiar na magra partilha.

8 O Colégio Agrícola também era chamado Agrotécnico, numa referência ao curso ali ministrado, desde 1953. Estudos sobre esse Colégio Agrícola são encontrados em Azevedo (2005).
} 
Quanto a estrutura do Colégio Agrícola, sugerimos a seguinte:

1 o ano - Matérias da Cultura Geral e Técnicas

20 ano - “ “ “ “ “ “ 9

$\mathrm{O} 3^{\circ}$ ano teria duas modalidades:

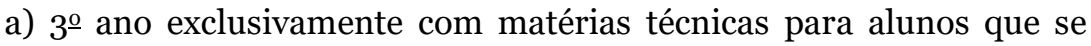
destinam as atividades agropecuárias.

b) $3^{\text {o }}$ ano exclusivamente com matérias de cultura geral, para os alunos que se destinam as Escolas Superiores que hajam concluído o 2o científico, se matricularem nesta 3 a série, mediante a existência de vagas e exame de seleção (COMISSÃO ESPECIAL..., 1962).

Um dos argumentos da Comissão para essa sugestão era que um grande número de alunos "por êle diplomado tem se encaminhado em sua maioria para o Curso Superior de Agronomia, tendo os referidos alunos logrado ótimas classificações nos vestibulares; funcionando desta maneira a semelhança do Colégio Universitário.” Essa situação, segundo Cunha (1985), era comum entre os egressos de cursos técnicos em todo o País, configurando um problema. Longe de conter os jovens no nível médio, os cursos técnicos abriam a possibilidade de prosseguimento dos estudos, não se efetivando a repressão da demanda por vagas nos cursos superiores. A Comissão, então, manifestou-se favoravelmente em relação à criação do Colégio Universitário, apenas se não fosse possível atender às reivindicações do Colégio Agrícola.

O Curso Agrotécnico era vinculado à Escola Superior de Agricultura (ESA) e, em função disso, o tema também foi discutido naquela Congregação. Em reunião no dia 06/11/1962, a Congregação da ESA, presidida pelo Professor José Alencar, entre outros assuntos, discutiu a questão do Colégio Agrícola. Um dos membros da Comissão, Professor Clibas Vieira, votou separadamente a favor da extinção do Colégio Agrícola e pela criação do Colégio Universitário. Os demais membros da Comissão indicaram ao Conselho a manutenção do Colégio Agrícola, desde que atendidas as necessidades mínimas de manutenção e funcionamento,

\footnotetext{
9 Transcrito como no original.
} 
como corpo docente próprio, verba própria e alojamento para os internos. Caso isso não fosse possível nem viável, a Comissão seria favorável à criação do Colégio Universitário. Entretanto, ressalvou a Comissão que a opção pelo Colégio Universitário não eliminava a necessidade de infraestrutura mínima. A Congregação discutiu a questão, conforme relatado na Ata n. 507, de 1962, aprovando o parecer da Comissão:

O Prof. Edson P. Magalhães propoz a aprovação do parecer dos outros membros da comissão, os professores Anibal J. A. Torres, Joaquim Matoso e Fernando A. S. Rocha, que é pela manutenção do Colégio Agrícola (Curso Técnico de Agricultura) uma vez satisfeitas as exigências mínimas (a) administração propria, subordinada ao Reitor; (b) corpo docente próprio; (c) verba propria especificada em orçamento; (d) predio proprio para administração e aulas; (e) dormitorio; (f) campos de esporte. Quanto a estrutura, sugere que o primeiro e segundo ano tenham matérias de cultura geral e técnicas e o terceiro ano, com duas modalidades: (a) exclusivamente com materias técnicas para os alunos que se destinam as atividades agropecuárias; (b) exclusivamente com materias de cultura geral para os que se destinam as Escolas Superiores. Caso a Administração não consiga proporcionar as condições mínimas exigidas, o parecer é favorável pela criação do Colegio Universitario. Porém, para o Colegio Universitario possa preencher suas finalidades as exigências (a) a (f) feitas para o Colégio Agrícola devem ser satisfeitas e, ainda, deve atender os candidatos a todas as unidades da Universidade. Postas em votação a proposta do Prof. Edson P. Magalhães recebeu onze votos - aprovada -, a do Prof Otto Andersen, 9 votos, e tres votos em branco" (UNIVERSIDADE..., 1962, Ata n. 507, grifo nosso).

O tema foi debatido na reunião do Conselho Universitário de 27/12/1962. A Comissão de Legislação e Ensino encarregada da questão, apontou vários problemas para a manutenção do Colégio Agrícola, repetindo as recomendações dadas da Ata n. 507: falta de professores específicos para o Curso Agrotécnico ${ }^{10}$, desviando os professores de suas funções nos cursos de graduação; falta de

10 O Curso Técnico de Agricultura ministrado pelo Colégio Agrícola também é chamado, nos documentos encontrados, de Agrotécnico. 
espaço para acomodar os alunos internos; falta de espaço para aulas teóricas, competindo com as aulas da graduação; e falta de verba própria no orçamento da UREMG. Todas essas carências traziam imenso prejuízo para a formação dos estudantes e para os cursos de graduação, que dividiam os parcos recursos com o curso Agrotécnico. A Comissão recomendou, por fim, que a manutenção do Colégio Agrícola fosse condicionada ao atendimento dessas demandas. E quanto ao Colégio Universitário, que ele fosse criado tão logo fosse possível. A Ata n. 95 do Consu traz o seguinte registro:

Curso técnico de Agricultura e Colégio Universitário - o parecer da Comissão de Legislação e Ensino foi baseado nos seguintes termos: $\mathrm{O}$ relatório da ilustre comissão V. Magcia. Designada para estudar o problema do Curso Técnico de Agricultura, traduz com muita realidade a situação precária em que vem sendo mantido aquele curso junto à ESA. Situação essa que repercute profundamente no seguinte:

1. Prejuízo para a formação moral e cívica dos adolescentes que frequentaram o curso;

2. Prejuízo para a formação intelectual e profissional de todos os frequentadores do Curso.

3. Perturbação no bom andamento do programa de várias cadeiras do Curso Superior de Agronomia, uma vez que instrutores e assistentes e até adjuntos têm sido desviados para suprir a falta dos professores do Curso Técnico de Agricultura. Esta situação é agravada com a permanente ocupação de (três) 3 salas de aulas teóricas. As providências sugeridas pela Comissão devem ser motivo de atenção para solução imediata.

A Comissão é pela continuação do referido Curso, desde que se procure satisfazer as seguintes condições:

1. Que seja criado um órgão diretor mais efetivo para dirigi-lo, ao em vez de se limitar ao um simples assessoramento junto à ESA.

2. Que seja organizado um regimento interno para o Curso com a participação de um Conselho de Ensino na solução de problemas que sejam próprios ao curso.

3. Que se contratem professores cuja finalidade principal seja a de lecionar para os alunos do Curso.

4. Que não haja desvio de professores da ESA para aquele curso.

5. Que se procure aliviar as salas do prédio de química, transferindo o 
curso para outro local.

6. Que não sejam admitidos novos alunos no Internato, enquanto o Curso não contar com instalações próprias.

7. Que conste do orçamento da UREMG verba própria para a manutenção do Curso.

Quanto ao Colégio Universitário, não há que duvidar é uma necessidade. Somos de opinião que este Colégio deva ser criado tão logo haja condições de instalações e de pessoal para que possa funcionar regularmente. Este parecer depois de longamente discutido foi aprovado pelo colendo Conselho Universitário, com uma abstenção (UNIVERSIDADE..., 1962, Ata n. 95, grifo nosso).

Mais uma vez são ressaltadas a questão financeira e a importância de se confirmar a possibilidade de real atendimento das demandas do novo colégio. Essa preocupação residia no fato de o orçamento da UREMG ser regularmente insuficiente para as despesas da Instituição ${ }^{11}$. Esse assunto somente retornou à pauta em 24 de fevereiro de 1964. A Comissão de Legislação e Ensino ${ }^{12}$ recomendou a criação do Colégio Universitário e a transferência do curso Agrotécnico para a Escola Média de Agricultura de Florestal (Emaf), pertencente à UREMG, e a extinção do Colégio Agrícola no campus de Viçosa. Nessa ocasião, a pauta foi assim registrada:

Colégio Universitário e transferência do Curso Técnico de Agricultura para a Escola Média de Agricultura de Florestal - A Comissão de Legislação e Ensino, reexaminando a matéria acima e tendo conta o voto em separado do Prof. Edson Potsch Magalhães, é de parecer favorável à criação do Colégio Universitário tão logo seja possível, e à transferência do Curso Agrotécnico para Florestal. Dita transferência há de fazer-se gradativamente, de modo a não se admitir novos alunos em Viçosa para 1965, mas assegurandose aos que lá se encontram o direito de concluírem em Viçosa o

${ }^{11}$ É possível encontrar no arquivo histórico da UFV vários documentos que tratam dessa questão, desde cartas ao governador, solicitando o repasse de verbas retidas, até pedidos de adiantamento feito por servidores que passavam por necessidades materiais, por falta de pagamento.

${ }^{12}$ A cada reunião do Conselho, novos membros compunham as diversas comissões que avaliavam os diversos assuntos (finanças, legislação e ensino, entre outros). 
respectivo curso. A Comissão de Finanças subscreveu o parecer acima. Foi aprovado por unanimidade (UNIVERSIDADE..., 1964, Ata n. 103, grifo nosso).

Assim, definiu-se pela transferência do Curso Agrotécnico para Florestal (Emaf) e pela criação do Colégio Universitário no campus de Viçosa. O assunto, entretanto, retornou à pauta na reunião de 26 de novembro de 1964. A transferência do curso para Florestal seria inviável (não há informações que esclareçam essa inviabilidade). Decidiu-se pela última oferta de vagas para o Curso Agrotécnico no campus de Viçosa em 1965, com a instalação do Colégio Universitário em 1967. A representante dos estudantes foi contrária à decisão final, sendo, entretanto, voto vencido. A discussão teve o seguinte desfecho:

Transferência do Curso Técnico de Agricultura para Florestal e criação
do Colégio Universitário. "A Comissão de Legislação e Ensino,
reexaminando a matéria acima e tendo em conta o voto em separado da
Sta. Amélia Fitipaldi, considerando a impraticabilidade da
transferência do Curso Técnico de Agricultura para Florestal,
é de parecer que: a) em vista de, até o presente, não haver sido tomada
nenhuma resolução definitiva sobre a proposta transferência, se
realize, em Viçosa, em 1965, pela última vez o exame de
admissão para o curso Técnico de Agricultura; b) aos alunos do
Agrotécnico seja assegurado o direito de concluírem o curso em Viçosa;
c) se crie o Colégio Universitário tão logo seja possível; d) seja
estudada a possibilidade da instalação do Colégio Universitário em
1967, de modo a permitir o acesso a ele dos alunos do agrotécnico que
terminarem o 2o ano". A Comissão de Finanças subscreveu tal parecer.
A aprovação, com o voto em separado da Conselheira Amélia Fitipaldi,
assim redigido: "Como representante do corpo discente desta
Universidade e considerando ser de grande utilidade o curso
Agrotécnico, voto contra a extinção do referido curso desta
Universidade" (UNIVERSIDADE..., 1964, Ata n. 108).

Como é possível depreender dos excertos dos documentos citados, a criação do Colégio Universitário não foi uma unanimidade. Desde o início do debate havia resistência entre os docentes e entre os estudantes sobre sua criação. Percebemos os argumentos de natureza prática, como recursos para instalação e 
contratação de professores e técnicos, até aqueles de natureza ideológica, expostos pelo Professor Postch e pela representante discente na reunião de 26/11/64. Farinha pouca, meu pirão primeiro.

\section{ENTRE A FORMAÇÃO TÉCNICA E A FORMAÇÃO PROPEDÊUTICA: DILEMAS DE ONTEM E DE HOJE}

O debate que se fazia no âmbito nacional sobre o caráter da formação na educação secundária era vigoroso também no interior da UREMG. Constatamos, nos documentos consultados, uma tensão nos dois polos: aqueles favoráveis à formação propedêutica, com vistas à preparação do futuro aluno da graduação, e aqueles outros, que pretendiam uma formação mais integral, mais humanista, opções descritas nos documentos pelos defensores de cada uma delas. A opção entre a manutenção do Curso Agrotécnico e a criação do Coluni estava, obviamente, diretamente relacionada à concepção de formação profissional e de educação que defendiam as pessoas encarregadas dessa decisão.

Essa era a grande questão da educação brasileira, herdada de um passado de desigualdade e que pouco se resolveu nos anos seguintes: a dualidade estrutural. Segundo Acácia Kuenzer (2009), a formação de jovens no País era caracterizada pela dualidade que a dividia em dois ramos: para os filhos das classes trabalhadoras, a formação profissional ocorreria no ensino primário, com formação posterior em cursos direcionados para:

[...] o mundo do trabalho no nível ginasial: normal, técnico comercial e técnico agrícola. [...]. Para as elites, havia outra trajetória: o ensino primário seguido pelo secundário propedêutico, completado pelo ensino superior, este sim dividido em ramos profissionais. [...] Desse modo, a formação de trabalhadores e cidadãos no Brasil constituiu-se historicamente a partir da categoria dualidade estrutural, uma vez que havia uma nítida demarcação da trajetória educacional dos que iriam desempenhar as funções intelectuais ou instrumentais, em uma sociedade cujo desenvolvimento das forças produtivas delimitava claramente a divisão entre capital e trabalho traduzida no taylorismo- 
fordismo como ruptura entre as atividades de planejamento e supervisão de um lado, e de execução de outro (KUENZER, 2009, p. 27).

A esse respeito, Anísio Teixeira ressalta que mesmo nos cursos profissionalizantes de nível médio a presença de jovens das classes trabalhadoras era mínima, visto que na década de 1960 a matrícula nesses cursos era muito reduzida quando comparada à dos cursos secundários colegiais, representando 1,1\% da matrícula geral no ensino secundário no caso do curso de técnico agrícola (TEIXEIRA, 1967).

Assim, a decisão sobre manter ou não o curso Agrotécnico e criar ou não o Coluni, mantendo ou não as duas propostas concomitantemente, iria definir a concepção de educação adotada pela UREMG e defendida pelos que ali a representavam naquele momento. Apesar de a Lei n. 4.024/1961 ter definido a equivalência entre os cursos propedêuticos e técnicos para efeito de acesso aos cursos superiores, a dualidade não foi superada e a formação distinta continuou a existir (KUENZER, 2009). Na UREMG, esse fato ficou muito claro no processo de criação do Coluni, com a opção pela sua formação propedêutica.

O Colégio Universitário foi enfim criado, em março de 1965, pelo Conselho Universitário da então Universidade Rural do Estado de Minas Gerais. Conforme a Ata n. 113, que trouxe a discussão do anteprojeto do Estatuto da UREMG, o Colégio Universitário foi incluído na estrutura organizacional da Instituição. O Decreto n. 8.484, de 14 de julho de 1965, sancionado pelo então Governador do estado de Minas Gerais, José de Magalhães Pinto, aprovou o estatuto e o Colégio Universitário ficou vinculado à Diretoria Geral de Ensino.

A proposta de formação de jovens para ingressar na UFV, todavia, não nasceu com o Coluni. Segundo José Marcondes Borges:

Em relação ao início das aulas do Curso Complementar, em 1o de março de 1937, dizia John B. Griffing: "do Curso Complementar (precursor do Colégio Universitário dos nossos dias) sairão rapazes melhor 


\begin{abstract}
preparados, tornando assim possível o aumento em número de melhores profissionais, que romperão na vida prática sob a sempre crescente e acreditada influência da ESAV". Esse curso funcionou até 1943, quando a mudança verificada no ensino do País determinou sua extinção (BORGES, 1968, s. p.). ${ }^{13}$
\end{abstract}

A ideia da excelência no ensino vinha, portanto, acompanhando a evolução da instituição. Desde a chegada do Professor Rolfs a Viçosa para a criação da Esav, essa perspectiva acompanhava todos os administradores, técnicos e estudantes. A formação de jovens para compor os quadros discentes soava como natural no cenário do ideário esaviano. No dizer de Azevedo, havia que melhorar a semente (AZEVEDO, 2005).

O primeiro regimento foi aprovado em 24 de outubro de 1966, pelo Conselho Universitário. Como primeira finalidade, trazia a necessidade de recrutamento para os cursos de graduação da UREMG. Os demais objetivos declarados, no entanto, parecem não ter saído do papel. Métodos de ensino diferenciados e articulação com outras escolas da sociedade não foram objeto da atenção do Colégio nos anos que se seguiram. A preocupação com a formação da nova geração de esavianos era o foco principal, se não o único. O regimento prescrevia as seguintes finalidades para o Colégio:

a - completar, nos termos da Lei no 4.024, a educação de nível médio dos alunos que nêle se matricularem, levando em conta as necessidades de recrutamento da UREMG;

b - aplicar, no seu campo de atividades profissionais, métodos de ensino e educação que sirvam de modelo à comunidade universitária;

c - criar, nos alunos que o freqüentam, espírito de indagação e crítica pelo desenvolvimento de raciocínio que leve o estudante a pensar mais logicamente, procurando precisar sua convocação profissional;

13 Quando da pesquisa documental no arquivo histórico da UFV, foi localizada uma correspondência do presidente do Diretório Acadêmico Arthur Bernardes (Daab) - entidade representativa dos estudantes do Curso de Agronomia da ESA, Ruy Caldas, endereçada ao Diretor da ESA, Prof. José Alencar, fazendo referência a um cursinho preparatório para o vestibular da UREMG, promovido pelo Daab. 
d - despertar a consciência do estudante para a natureza e os problemas de sua própria sociedade e para sua responsabilidade como cidadão, dentro dela;

e - dar à Universidade plena consciência de suas responsabilidades, em relação ao ensino de grau médio, quer como centro formador de professores e educadores que nela trabalham, quer como centro que recebe os alunos que se preparam para o estudo e o trabalho, em nível universitário;

f - o Colégio Universitário, na realização de seus objetivos, articular-seá com outros colégios e organizações que congreguem professores dêste grau de ensino, de modo que suas experiências e métodos de ensino sejam compartilhados com essas outras instituições (REGIMENTO, 1967, p. 2-3, grafado como no original).

O objetivo privilegiado de preparar jovens candidatos aos cursos de graduação se alinhava às demandas da educação naquele momento: contenção dos egressos do ensino médio que demandariam vagas no ensino superior com a oferta do curso técnico em Florestal, seleção dos melhores com o Coluni, em Viçosa, haja vista os problemas com a qualidade da educação recebida na escola de nível médio, deficiência essa denunciada por Anísio Teixeira ao se referir à escola brasileira. Segundo ele, "arcaicas nos seus métodos e ecléticas, se não enciclopédicas, nos currículos, não são de preparo verdadeiramente intelectual, não são práticas, não são técnico-profissionais, nem são de cultura geral, seja lá em que sentido tomarmos o termo" (TEIXEIRA, 1967, p. 21). No dizer de Anísio Teixeira, a ampliação do acesso (que não ampliou tanto assim ${ }^{14}$ ) trouxe a deterioração da qualidade do ensino, com a contratação de professores sem qualificação, redução da carga horária no curso primário (para atender à demanda sem aumento do número de salas e escolas) e um método que pouco contribuía com a aprendizagem. Essa condição também se replicava na escola secundária, que naquele momento estava "funcionando em turnos, como as primárias, improvisadas, como as primárias, de puro ensino verbalístico, e, ainda como as primárias, puramente preparatórias” (TEIXEIRA, 1967, p. 34).

\footnotetext{
${ }_{14}$ Em 1953, 7,6\% dos alunos que se matriculavam no ensino primário concluíam o curso; em 1963, esse número equivalia a 8,2\% (TEIXEIRA, 1967, p. 24-25).
} 


\section{À GUISA DE CONCLUSÃO}

O objetivo do presente artigo foi apresentar os dilemas vivenciados na UREMG quando da criação do Colégio Universitário, no que dizia respeito à manutenção ou não do curso Agrotécnico. Após intensos debates, a instituição optou por extinguir o Curso Agrotécnico e criar o Colégio Universitário, nos moldes da Lei n. 4.024/1961, com o intuito de preparar os jovens para o vestibular. O objetivo da criação do Colégio Universitário era selecionar os melhores candidatos e prepará-los para o acesso ao Curso de Agronomia (principal curso da instituição naquela época).

Um dos principais argumentos do grupo que defendia a criação do Colégio Universitário era que os estudantes que passavam pelo Curso Agrotécnico se dirigiam ao curso superior de Agronomia, o que não justificava a manutenção do curso técnico, que demandava alta soma de recursos. A precária condição financeira da Instituição justificava tal preocupação. A decisão do Conselho Superior, em 1964, foi de transferência do Curso Agrotécnico para a Emaf e criação do Colégio Universitário, que teve sua primeira turma ofertada em 1966.

Em Viçosa, o impasse sobre a manutenção do Curso Agrotécnico foi vencido pelo Colégio Universitário. Na UFV, como no restante do País, a opção pela formação propedêutica se efetivava, tendo por objetivo a formação de melhores candidatos ao vestibular, especialmente para o Curso de Agronomia, que, na análise de Florestan Fernandes, era um dos "cinco setores essenciais" entre todas as escolas de nível superior. Esses setores eram: agronomia, engenharia, medicina, química industrial e serviços sanitários (FERNANDES, 1966, p. 33).

O Colégio Universitário se manteve ofertando o terceiro ano do então segundo grau até 1981. Em 1982 passou a ofertar as três séries do segundo grau. Em 2001 se converteu em Colégio de Aplicação, como se mantém até os dias atuais. 


\section{REFERÊNCIAS}

ANDRADE, Cibele Yahn de. Acesso ao ensino superior no Brasil: equidade e desigualdade social. Revista Ensino Superior, Unicamp, Campinas, 31 jul. 2012. Disponível em:

https://www.revistaensinosuperior.gr.unicamp.br/artigos/acesso-ao-ensinosuperior-no-brasil-equidade-e-desigualdade-social. Acesso em: out. 2015.

AZEVEDO, Denílson Santos de. Melhoramento do homem, do animal e da semente: o projeto político-pedagógico da Escola Superior de Agricultura e Veterinária do Estado de Minas Gerais (1920-1948), organização e funcionamento. 2005. 225 f. Tese (Doutorado em Educação) - Universidade de São Paulo, São Paulo, 2005.

BORGES, José Marcondes. Escola Superior de Agricultura: origem desenvolvimento - atualidade. Viçosa: Imprensa Universitária da UREMG, 1968.

BRASIL. Decreto n. 8.659, de 5 de abril de 1911. Aprova a lei orgânica do ensino superior e do fundamental na República. Disponível em:

http://www2.camara.leg.br/legin/fed/ decret/1910-1919/decreto-8659-5-abril1911-517247-publicacaooriginal-1-pe.html. Acesso em: out. 2015.

BRASIL. Decreto-Lei n. 464, de 11 de fevereiro de 1969. Estabelece normas complementares à Lei n. 5.540, de 28 de novembro de 1968, e dá outras providências. Disponível em:

http://www2.camara.leg.br/legin/fed/declei/1960-1969/decreto-lei-464-11fevereiro-1969-376438-publicacaooriginal-1-pe.html. Acesso em: set. 2015.

BRASIL. Decreto-Lei n. 477, de 26 de fevereiro de 1969b. Define infrações disciplinares praticadas por professores, alunos, funcionários ou empregados de estabelecimentos de ensino público ou particulares, e dá outras providências. Disponível em: http://www2.camara.leg.br/legin/fed/declei/19601969/decreto-lei-477-26-fevereiro-1969-367006-norma-pe.html. Acesso em: fev. 2016.

BRASIL. Emenda Constitucional n. 95, de 15 de dezembro de 2016. Altera o ato das disposições constitucionais transitórias, para instituir o Novo Regime Fiscal, e dá outras providências. Brasília, DF: Casa Civil, 2016.

BRASIL. Lei n. 13.467, de 13 de julho de 2017. Reforma trabalhista. Altera a Consolidação das Leis do Trabalho (CLT), aprovada pelo Decreto-Lei n. 5.452, de $1^{\circ}$ de maio de 1943, e as Leis n. 6.019, de 3 de janeiro de 1974, 8.036, de 11 de 
maio de 1990, e 8.212, de 24 de julho de 1991, a fim de adequar a legislação às novas relações de trabalho. Disponível em:

http://www2.camara.leg.br/legin/fed/lei/2017/lei-13467-13-julho-2017785204-norma-pl.html. Acesso em: nov. 2017.

BRASIL. Lei n. 4.024, de 20 de dezembro de 1961. Fixa as diretrizes e bases da educação nacional. Disponível em:

http://www.planalto.gov.br/ccivil_03/leis/l4024.htm. Acesso em: out. 2013.

BRASIL. Lei n. 5.540, de 28 de novembro de 1968. Fixa normas de organização e funcionamento do ensino superior e sua articulação com a escola média, e dá outras providências. Disponível em:

http://www.planalto.gov.br/CCivil_o3/leis/L5540.htm. Acesso em: ago. 2015.

BRASIL. Lei n. 5.692, de 11 de agosto de 1971. Fixa as Diretrizes e Bases para o ensino de $1^{\circ}$ e $2^{\circ}$ graus e dá outras providências. Disponível em:

http://www.planalto.gov.br/ ccivil_03/leis/l5.692.htm. Acesso em: jul. 2014.

COMISSÃO ESPECIAL sobre os problemas do Curso Técnico e do Colégio Universitário. [Correspondência] 22 out. 1962, Viçosa [para] Reitor da Universidade Federal de Viçosa. 3 f. Sugestões da Comissão sobre criação do Colégio Universitário.

CUNHA, Luiz Antônio. A universidade crítica: o ensino superior na República Populista. Rio de Janeiro: Francisco Alves, 1983.

CUNHA, Luiz Antônio. A universidade reformada: o golpe de 1964 e a modernização do ensino superior. Rio de Janeiro: Francisco Alves, 1988.

CUNHA, Luiz Antônio. Educação e desenvolvimento social no Brasil. 5 . ed. Rio de Janeiro: Francisco Alves, 1980.

CUNHA, Luiz Antônio. Educação e desenvolvimento social no Brasil. 8. ed. Rio de Janeiro: Francisco Alves, 1985.

FERNANDES, Florestan. Educação e sociedade no Brasil. São Paulo: Ed. da USP, 1966.

GERMANO, José Willington. Estado militar e educação no Brasil (10641985). 5. ed. São Paulo: Cortez, 2011.

KUENZER, Acácia Zeneida. A concepção de ensino médio e profissional no Brasil: a história da construção de uma proposta dual. In: KUENZER, Acácia Zeneida (org.). Ensino Médio: construindo uma proposta para os que vivem do trabalho. 6. ed. São Paulo: Cortez, 2009. p. 37-33. 
LOPES, Thiago. A necessidade estratégica da expansão do ensino superior com qualidade. Carta Maior, o1 jan. 2014. Disponível em:

http://cartamaior.com.br/?/Editoria/Educacao/A-necessidade-estrategica-daexpansao-do-ensino-superior-com-qualidade/13/29915. Acesso em: out. 2015.

MINAS GERAIS. Decreto 8.484, de 14/07/1965. Aprova o estatuto da Universidade Rural do Estado de Minas Gerais. Disponível em:

http://www.almg.gov.br/consulte/legislacao/completa/completa.html?tipo=de $c \&$ num $=8484 \&$ comp $=\& a n o=1965$. Acesso em: fev. 2016.

ROMANELLI, Otaíza de Oliveira. História da educação no Brasil (1930/1973). 13. ed. Petrópolis: Vozes, 1991.

TEIXEIRA, Anísio. Educação não é privilégio. 2. ed. São Paulo: Companhia Editora Nacional, 1967.

UNIVERSIDADE RURAL DO ESTADO DE MINAS GERAIS. Conselho Universitário. Ata da reunião realizada no dia 13 de outubro de 1962. Livro 31, Ata n. 94.

UNIVERSIDADE RURAL DO ESTADO DE MINAS GERAIS. Conselho Universitário. Ata da reunião realizada no dia 27 de dezembro de 1962. Livro 31, Ata n. 95.

UNIVERSIDADE RURAL DO ESTADO DE MINAS GERAIS. Conselho Universitário. Ata da reunião realizada no dia 24 de fevereiro de 1964. Livro 32, Ata n. 103.

UNIVERSIDADE RURAL DO ESTADO DE MINAS GERAIS. Conselho Universitário. Ata da reunião realizada no dia 26 de novembro de 1964. Livro 32, Ata n. 108.

UNIVERSIDADE RURAL DO ESTADO DE MINAS GERAIS. Conselho Universitário. Ata da reunião realizada no dia 26 de março de 1965. Livro 32, Ata n. 113.

UNIVERSIDADE RURAL DO ESTADO DE MINAS GERAIS. Escola Superior de Agricultura. Ata da reunião realizada no dia 6 de novembro de 1962. Livro 12, Ata n. 507.

UNIVERSIDADE RURAL DO ESTADO DE MINAS GERAIS. Regimento do Colégio Universitário. Viçosa. 1967.

WARDE, Mirian Jorge. Educação e estrutura social: a profissionalização em questão. 2. ed. São Paulo: Cortez e Morais, 1979. 
JOANA D'ARC GERMANO HOLLERBACH é licenciada em História; mestre em Educação pela Universidade Federal de Minas Gerais (UFMG); doutora em Educação pela Universidade Federal de São Carlos (UFSCar) e professora Adjunta II do Departamento de Educação da Universidade Federal de Viçosa (UFV), em Viçosa/MG, atuando nas áreas de políticas para educação básica e história da educação.

E-mail: joanadarcgermano@gmail.com

(D) http://orcid.org/0000-0002-3931-7836

Recebido em: 30 de janeiro de 2018

Aprovado em: 23 de dezembro de 2018 